\title{
Evaluation of nesting behavior of individual laying hens in an enriched colony housing by using RFID technology
}

\author{
Jofran L. Oliveira ${ }^{1,5}$, Hongwei Xin ${ }^{2,5^{*}}$, Kailao Wang ${ }^{3,5}$, Yang Zhao ${ }^{4,5}$ \\ (1. Department of Agricultural and Environmental Engineering, Universidade Federal de Rondonópolis, Mato Grosso 78735-901, Brazil; \\ 2. The University of Tennessee Institute of Agriculture, Knoxville, Tennessee 37996, USA; \\ 3. Department of Biosystems Engineering, Zhejiang University, Zhejiang 310058, China; \\ 4. Department of Agricultural and Biological Engineering, Mississippi State University, Mississippi 39762, USA, \\ 5. Formerly Department of Agricultural and Biosystems Engineering, Iowa State University, Ames, Iowa 50011-3270, USA)
}

\begin{abstract}
The US egg industry is progressively adopting alternative housing systems for laying hens. Provision of nesting places accommodates natural behaviors and may improve the welfare of the laying hen. However, some fundamental questions remain about nesting behaviors of hens under different housing conditions, which would impact system design and management. For instance, how long does a hen use nest per day for egg laying or nest exploration? How many hens nest simultaneously? In such schemes, information on hens' behavioral and production responses of hens remains relatively sparse. The primary objective of this work was to demonstrate that RFID technology can be used to continuously quantify dynamic nesting behaviors of individual laying hens in a 60-hen enriched colony housing (ECH). Results show that hens spent on average $63.7 \pm 1.4 \mathrm{~min}($ mean $\pm \mathrm{SE})$ in the nest box and made $23.4 \pm 0.7$ nest visits during a $16 \mathrm{~h}$ daily light period. Time spent in and visits to the nest box during the $6 \mathrm{~h}$ laying period accounted for $56 \%$ and $45 \%$ of the light-period value, respectively. Maximum nest occupancy was $29.0 \% \pm 0.4 \%$. Three distinct phases of egg production in nest boxes were observed: initial $(1.5 \mathrm{~h})$, peak $(3.2 \mathrm{~h}$, egg laying rate of $0.24 \pm 0.01 \mathrm{eggs} / \mathrm{min})$, and late $(1.3 \mathrm{~h})$. The majority $(95.1 \% \pm 0.6 \%)$ of the daily eggs were laid in the nest box. Considerable variations in nesting behavior among individual hens and day-to-day variations for a given hen were observed. The RFID system will enable researchers to examine the impacts of resource allocations on nesting behaviors of laying hens in alternative hen housing.
\end{abstract}

Keywords: animal welfare, egg production, RFID, alternative hen housing, individual behaviors

DOI: $10.25165 /$ j.ijabe.20191206.5129

Citation: Oliveira J L, Xin H W, Wang K L, Zhao Y. Evaluation of nesting behavior of individual laying hens in an enriched colony housing by using RFID technology. Int J Agric \& Biol Eng, 2019; 12(6): 7-15.

\section{Introduction}

The productivity of laying hens has improved considerably over the past 60-70 years because of the advancement in dietary nutrition, genetics, disease prevention, controlled production environment, and husbandry equipment. At the same time, welfare standards of hens continue to elevate, and some of the criteria (e.g., allocation of enrichment, housing systems, and management practices) are subject to debate ${ }^{[1-4]}$. Transitioning of egg production systems from conventional cage to alternative housing (e.g., enriched colony, aviary cage-free) is increasingly occurring in various parts of the world, especially in Europe and the United States, to meet animal welfare requirements or legislation $^{[5,6]}$.

Considering that laying hens have strong nesting motivation as a behavioral need ${ }^{[7,8]}$, enriched colony housing $(\mathrm{ECH})$ systems have been developed to accommodate such behavior, thereby improving animal welfare, by providing enclosures such as plastic curtains

Received date: 2019-05-06 Accepted date: 2019-09-24

Biographies: Jofran L. Oliveira, PhD, Adjunct Professor, research interests: precision livestock farming, Email: jofran@ufmt.br; Kailao Wang, Graduate Research Assistant, research interests: image processing for animal behavior, Email: wangkailao@zju.edu.cn; Yang Zhao, PhD, Assistant Professor, research interests: precision livestock farming, Email: yzhao@abe.msstate.edu.

*Corresponding author: Hongwei Xin, PhD, Dean, Director and Professor, research interests: animal production systems engineering. The University of Tennessee Institute of Agriculture, Knoxville, Tennessee 37996, USA. Tel: +1-865-974-7105, Email: hxin2@utk.edu. and turf mat surface in nest boxes ${ }^{[8-11]}$. Nesting is one of the important behaviors that has been retained during the hen's domestication $^{[12,13]}$. It consists of the exploration of nest places followed by sitting (the period when the hen sits and actively prepares for the egg laying), also known as pre-laying behavior, and subsequent oviposition ${ }^{[14]}$. In the absence of an appropriate nest location, the hen may extend the pre-laying phase by exploring other places, reducing the time for sitting ${ }^{[15]}$ or delaying the oviposition $^{[16]}$. Due to hormonal influences associated with ovulation, oviposition usually occurs in a short period of the day, and consequently, the pre-laying behavior of some hens kept in a group housing will occur simultaneously ${ }^{[17]}$. Literature has shown that social factors have a great impact on the time spent in the nest ${ }^{[18]}$, that the laying hens have a preference on occupied nests ${ }^{[19]}$, and that hens react to the aspect of the nest box, but are inconsistent in their use of a particular one ${ }^{[20,21]}$. However, little is known about the dynamics of nesting among hens in the same group, and some questions remain to be addressed. For instance, how does nesting time of the same hen change from one day to the next? How long do hens use nest box each day? How many hens simultaneously occupy the nest box? Answers to these questions would help to understand nesting behavior of hens and their interactions under certain physical conditions, which will be conducive to housing system design to accommodate the biological needs of hens while maximizing utilization of the resources.

The use of automatic measurement or monitoring systems in livestock facilities has provided information to better understand animal well-being. However, the traditional method (e.g., visual 
analysis) used to assess animal behaviors is dauntingly time-consuming and labor-intensive for addressing behavioral characteristics of individual animals. Radio Frequency Identification (RFID) system has been used to study animal behaviors ${ }^{[22-25]}$. It consists of a reader with a decoder to interpret the acquired data, scanning antenna, and pre-programmed transponders. RFID transponders can be active when a power source is used, or passive when the transponder is powered by the antenna. RFID systems were used to track laying hen behaviors automatically ${ }^{[26]}$, investigate laying hens' behavior in a preference chamber ${ }^{[27]}$, and evaluate the impacts of outdoor stocking density on the welfare and behavior of free-range laying hens ${ }^{[28]}$. Several tracking systems were used to study individual laying hens behaviors, and the strengths and weaknesses of each, as well as the environment or conditions suitable for using them, were discussed ${ }^{[29]}$.

Although some studies have been conducted to evaluate animal behaviors with the aid of RFID ${ }^{[30,31]}$, information regarding nesting behaviors of laying hens in ECH is incipient. Such information can build the baseline of such behavior in commercial ECH and implies future advances in management practices and the design and allocation of enrichments.

In the first part of a larger experiment that we conducted to assess feeding and nesting behavior of individual laying hens in $\mathrm{ECH}$, one Ultra High Frequency (UHF) RFID system was developed, validated ${ }^{[32]}$ and used to evaluate the impact of feeder space on feeding behavior ${ }^{[33]}$. The primary objective of the work reported in this paper was to demonstrate that RFID technology can be used to continuously quantify dynamic nesting behaviors of individual laying hens in a group-housing condition. The usefulness of the system was then illustrated by characterizing nesting behavior of Hy-Line W-36 laying hens in an ECH, including: daily time spent in the nest box (TS, min/hen-d), daily frequency of visits to the nest box (FV, visits/hen-d), number of visits per egg laid in the nest box (VE, visits/egg), simultaneous occupancy of the nest box (SO, \%), oviposition time (OT, hh:mm), and oviposition place (OP, \% eggs laid in the nest, middle or scratch areas), and nesting association (percentage of nesting time that the hens spend with one another). Variations in nesting behaviors among the individual hens and day-to-day variations for a given hen were also elucidated.

\section{Materials and methods}

The Iowa State University Institutional Animal Care and Use Committee-IACUC had approved the experimental protocol (Log \# 6-15-8038-G).

\subsection{Animals and housing}

Sixty Hy-Line W-36 (white) laying hens at 21 weeks of age (WOA) were obtained from a commercial farm with enriched colony housing in central Iowa. The pullets (young hens before lay) had been reared in standard rearing cages with the following conditions: $0.61 \mathrm{~m}$ long $\times 0.76 \mathrm{~m}$ wide each, 18 birds/cage $\left(258 \mathrm{~cm}^{2} / \mathrm{bird}\right)$, two nipple drinkers, feed through with available space of $3.4 \mathrm{~cm} / \mathrm{bird}$, and galvanized wire-mesh floor. At 17 WOA, the pullets were transferred to the commercial enriched colony hen houses equipped with enriched colony system (AVECH II, Big Dutchman, Vechta, Germany), where they were housed in 60-bird colonies with a stocking density of $750 \mathrm{~cm}^{2}$ floor area/bird.

The top tier of a double-tier ECH module, measuring $3.73 \mathrm{~m}$ long $\times 1.91 \mathrm{~m}$ wide $\times 1.91 \mathrm{~m}$ high $($ Big Dutchman, Vechta, Germany) was used in this experiment (Figure 1). The ECH module, located in a research laboratory at Iowa State University, featured a space allocation of $976 \mathrm{~cm}^{2} /$ hen of floor area which included the nest box $\left(85.4 \mathrm{~cm}^{2} /\right.$ hen $)$, scratch area $\left(85.4 \mathrm{~cm}^{2} / \mathrm{hen}\right)$, perches $(15.7 \mathrm{~cm} / \mathrm{hen})$, nipple drinkers $(10$ hens/drinker), feeder space $(12.3 \mathrm{~cm} / \mathrm{hen})$, tier height of $56 \mathrm{~cm}$, manure belt underneath, along with room heating and humidification to maintain the comfortable temperature and humidity. The nest boxes had orange-colored flexible curtains and artificial turf mat. Feeder troughs were located on both sides of the ECH. Manure was collected on a plastic tarp placed underneath the colony tier and removed once or twice a week. No litter, feed or other substrate was added to scratch pad area.

The hens were fed twice daily at 09:00 and 17:00 (ad libitum) with the same feed as used on the commercial farm where the hens were sampled. A photoperiod of $16 \mathrm{~h}$ light and $8 \mathrm{~h}$ dark (16L:8D) as practiced on the farm was used, with lights on at 05:00 and lights off at 21:00. The range of the light intensity was 13-120 lx across the top tier colony, with the lower intensity (13 lux) near the nest box area and the higher intensity near the scratch pad area (120 lx).
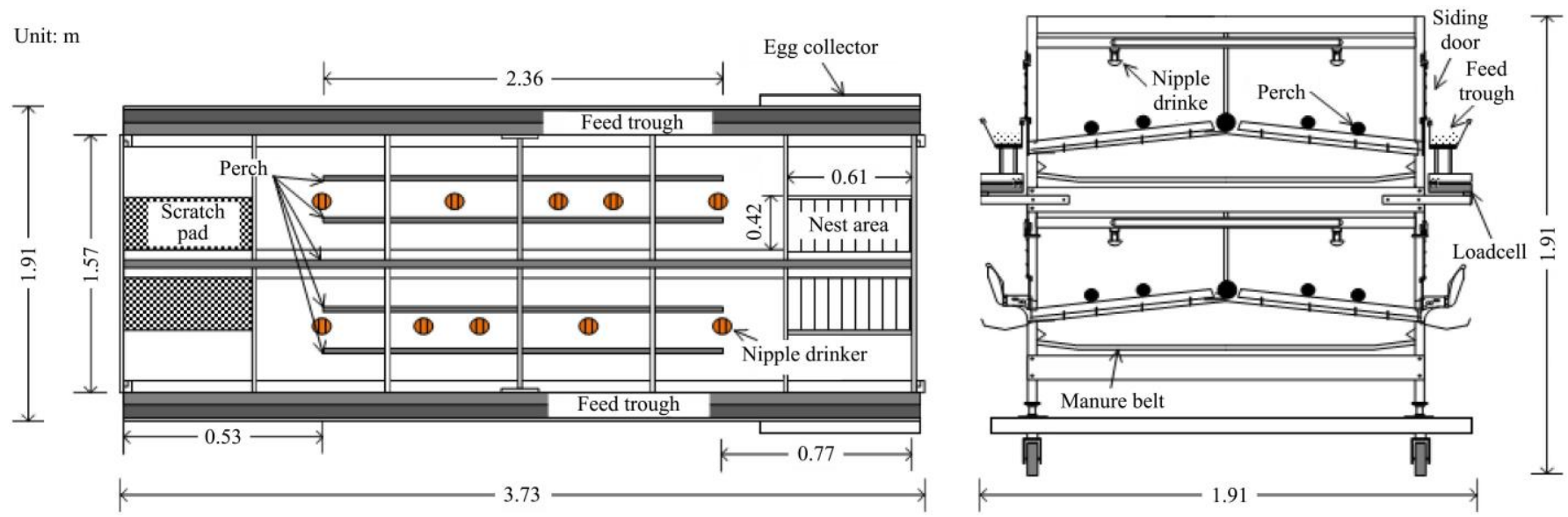

Figure 1 Top-view (left) and side-view (right) schematic drawings of the enriched colony module used in the experiment

Eggs laid during the experiment period were manually gathered daily at 17:00 from the egg belts and nest eggs collectors that were made of wooden troughs $(0.65 \mathrm{~m}$ long $\times 0.30 \mathrm{~m}$ wide $\times$ $0.20 \mathrm{~m}$ high) situated where the egg belt normally was, covering the nest width (Figure 1). Location of eggs was recorded as nest, middle or scratch area. Eggs possibly laid in the space between the nest curtain and the feeder were registered as nest eggs. Similarly, eggs possibly laid in the space between the scratch pad and the feeder were registered as scratch-pad eggs. Eggs were never observed to roll from one section to another. Upon transfer 
from the commercial farm to the ECH module in the research lab, the hens were given 7-day acclimation. Another 2-day acclimation was given after attachment of the RFID tags to the hen's leg. The data collection lasted $14 \mathrm{~d}$, with the first two days still considered part of the acclimation period. During the acclimation period, feed and water use and egg production were monitored to ensure that the hens were feeding, drinking and producing normally.

\subsection{Instrumentation}

The top tier colony was instrumented to monitor real-time feed and water use, record egg production (timing and number), and track the individual hens. Calibrated load-cell scales (Rice Lake RL1040, Rice Lake, WI) were used to weigh the nest eggs collectors (one load cell per collector) continuously (every second) with a maximum measurement error $<0.1 \%$ of the total weight measured. This information was used to determine the timing when the nest eggs were deposited in the egg collector. Details on the calibration of the load cells were previously described ${ }^{[32]}$.

Two cameras (IP Pro 3 Megapixel Bullet, DSS-BFR3MP, Backstreet Surveillance, Salt Lake City, UT) were installed on the ceiling above the ECH module and used to record the hen behaviors at two frames per second (fps). Video files were stored in 8 terabyte storage (two hard drives) of one NVR system (DSS-NVR5816, Backstreet Surveillance, Salt Lake City, UT).

Air temperature, relative humidity $(\mathrm{RH})$ and carbon dioxide $\left(\mathrm{CO}_{2}\right)$ concentration of the hen room were measured and recorded. All sensors were connected to a compact FieldPoint Module, and data recorded using a LabVIEW program (National Instruments Co., Austin, TX, USA). The research lab used an automatically controlled ventilation system that consisted of an environment controller (Varifan ECS-3C, Quebec, Canada), two variable speed exhaust fans (Multifan, Vostermans Ventilation, Bloomington, IL, USA), and a supplemental heating and cooling system. The room temperature was maintained at $23^{\circ} \mathrm{C} \pm 1^{\circ} \mathrm{C}$ (mean \pm SE) throughout the experiment.

\subsection{RFID system}

Nesting behavior was evaluated using one UHF RFID system that consisted of four antennas (Square A1030, $30 \mathrm{~cm} \times 30 \mathrm{~cm} \times$ $0.65 \mathrm{~cm}$ thick, TransTech Systems) located on both sides of the nest box, one 4-channel reader (ThingMagic Mercury M6, 865$928 \mathrm{MHz}$ operating frequency, TransTech Systems), 60 individual passive tags (902-928 MHz, PT-103, tie-wrap tag passive Gen 2 UHF, TransTech Systems), and a data acquisition (DAQ) system. The readers were connected to a host computer that processed the tag data through an RJ45 (Registered Jack, 10/100 Base-T Ethernet). The tag protocol was EPCglobal Gen 2 (ISO 18000-6C) with Digital Rights Management (DRM). The data acquisition program was written in C\# (C Sharp) based on Application Programming Interface (API), and the data were stored as text files.

One tag was loosely attached to each hen's leg with a zip tie. A hen was registered as nesting when the tagged leg was inside the nest box. The RFID system continuously registered hens inside the nest box, but not if the tagged leg was outside the nest mat while the rest of the body was inside the nest box, which corresponded to broken data. Intermittent brief breaks up to $30 \mathrm{~s}$ were considered as part of a nesting event, verified by video as well as previously validated ${ }^{[32]}$.

\subsection{Measurements and data processing}

Load cells were used to determine group-level production of nest eggs and determine the OT. The data were collected every second via a program developed in LabVIEW and then processed using EXCEL VBA programs. From the 12 days of load cells data collection, days 5 and 11 presented system disconnections with the generation of corrupted files and therefore the data from these two days were discarded. The OT was calculated by averaging the time that the first eggs (start time) and last eggs (end time) were registered in the nest eggs collectors. The OP was determined by calculating the average of the daily percentage of eggs laid in the three areas described as nest, middle, and scratch areas.

Data collected with the RFID system consisted of the time (hh:mm:ss:ms) when a specific hen (tag \#) was detected nesting. The number of hens detected by the RFID system was compared to and validated by that determined by the video system, i.e., human visual labeling ${ }^{[32]}$. The overall accuracy of the RFID system relative to the video observation was (mean $\pm \mathrm{SD}$ ) $91.4 \% \pm 1.7 \%$ $(n=78)$. Data analysis and processing were done using $\mathrm{R}$ and EXCEL VBA programs to describe the response variables TS, FV, and SO. Data analysis was performed considering two different periods of daily time: 1) Light period (05:00-21:00), and 2) Laying period including the pre-laying phase of nest exploring (05:00-11:00). The laying period was defined after a preliminary evaluation of the nest occupancy and egg laying rate data. VE was calculated as the ratio of the number of nest visits to eggs laid in the nest box.

Presence of individual hens in the nest box was used to delineate nest box usage of the hens and their nesting association (i.e., percentage of total nesting time when they nested with other hen or hens). The day-to-day consistency in nesting pattern, as measured by the longest duration of stay in the nest box, was assessed for each hen. This longest stay duration was termed 'main nest visit'. Visits other than the main nest visit were considered random visits, and FV of the hen was compared with the average FV for the laying period to classify as intense (FV of the hen > Average FV), or moderate (FV of the hen $\leq$ Average FV). Similarly, the average TS for the laying period was used to classify the usage of the nest box as intense (TS of the hen > Average TS) or moderate (TS of the hen $\leq$ Average FV). The day-to-day variation of the main nest daily visit of individual hens with identified nesting patterns was further classified according to the timing of nest visit.

After evaluation of all individual nest box usage data, nesting patterns were categorized into 5 groups according to the following criteria: 1) clear presence of nesting pattern (when the main nest visit is consistently observed during the laying period on most of the experiment days) with few or no random visits (FV $\leq$ 10.4 visits/d); 2) clear presence of nesting pattern, with moderate use of the nest box (TS $\leq 35.9 \mathrm{~min} / \mathrm{d}$ ) and several random visits (FV > 10.4 visits/d); 3) clear presence of nesting pattern, with intense usage of the nest box (TS $>35.9 \mathrm{~min} / \mathrm{d}$ ) during the laying period, with several random visits ( $\mathrm{FV}>10.4$ visits/d); 4) no clear nesting pattern, despite intense usage of the nest box (TS > $35.9 \mathrm{~min} / \mathrm{d}$ ) and; and 5) no clear nesting pattern, with moderate usage of the nest box (TS $\leq 35.9 \mathrm{~min} / \mathrm{d})$.

Association was considered when two or more birds used the nest box simultaneously during the laying period. A matrix was constructed for the amount of time that each bird was associated with others for each day evaluated. The matrices were symmetric along the diagonal (if bird A nested with bird B, then bird B must have nested with bird A). The diagonal represented the total time that the bird spent in the nest box, and it was used to create the matrix of percentage time spent with each other (the amount of 
time that bird A spent with bird B divided by the total time that bird A spend in the nest box during the observation day). These matrices were not symmetric about the diagonal (Although bird A and $B$ spent the same time together in the nest box, they individually spent different time in the nest box during the observation day, and consequently their percentage time spent together was different). The association matrix accounted for the number of birds that spent at least $X \%$ of their time together inside the nest box in the laying period during $Y$ days, with $X$ ranging from 0 to $100 \%$, and $\mathrm{Y}$ ranging from 1 to $12 \mathrm{~d}$.

\subsection{Statistical analysis}

Data were tested for homoscedasticity and normality. The data for TS and FV were square root transformed and analyzed as repeated measures using JMP 13.2.1 (SAS Campus Drive, Cary, $\mathrm{NC})$, following the mixed linear model:

$$
y_{j k}=\mu+b_{j}+\gamma_{k}+e_{j k}
$$

where, $y_{j k}$ is the response (TS or FV) value on day $k$ for bird $j ; \mu$ is the overall mean effect; $b_{j}$ is the random effect of bird $j ; \gamma_{k}$ is the fixed effect of the experimental day $k$; and $e_{j k}$ is the random error associated with bird $j$ on day $k$. Common assumptions were made on the random effects and errors in the repeated-measures model: the $b_{j}$ 's have mean of 0 and variance of $\sigma_{b}{ }^{2}$, are independent of each other, and of the $e_{j k}{ }^{\prime} s$; the $e_{j k}{ }^{\prime} s$ have mean of 0 and $e_{j k}{ }^{\prime} s$ with different $j$ values being independent of each other.

Results of TS and FV were obtained from the analysis of variance by fitting the mixed linear model (1) with the autoregressive correlation structure. The hypothesis tested was that there was no time effect on the response variables. Data of SO, OT, OP, VE, individual nesting pattern and nesting association were pooled over the experiment period, and descriptive statistics were provided. $p$-value of 0.05 or lower was considered significant. Results are presented as a least-squares mean \pm standard error (mean $\pm \mathrm{SE}$ ), unless otherwise specified.

\section{Results}

\subsection{Daily time spent in the nest box (TS)}

There was no evidence of time (day) effect on TS for the light period $\left(\mathrm{F}_{1,170.9}=0.85, p=0.32\right)$ or laying period $\left(\mathrm{F}_{1,179.8}=2.29, p=\right.$ $0.13)$. Therefore, data from all days were pooled to analyze variability in TS among the individual hens. The daily time spent in the nest box by each hen was determined, and individual variation in TS is shown in Figure 2.

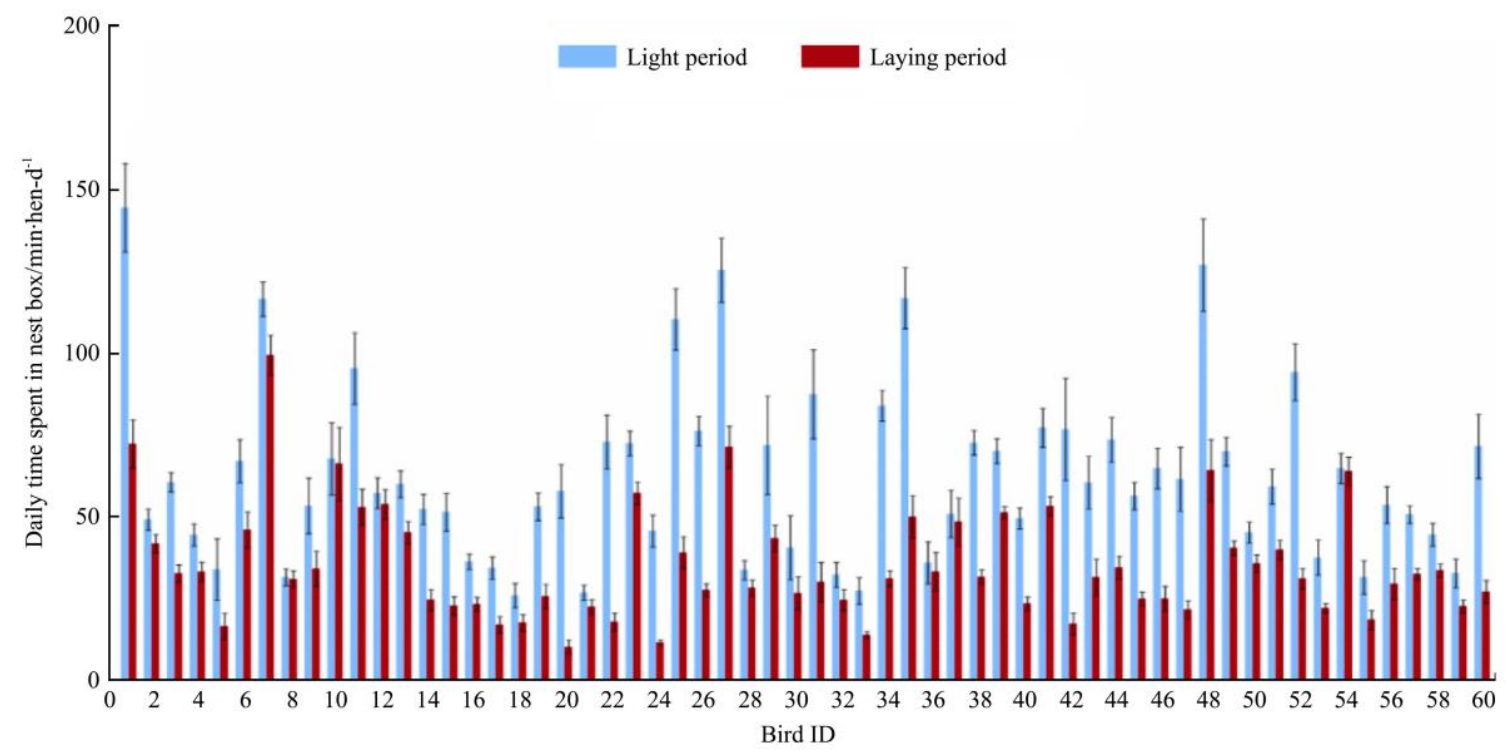

Note: The blue bars represent time spent during the light period (05:00 to 21:00) while the red bars represent time spent during the laying period (05:00 to 11:00).

Figure 2 Variation in daily time spent in the nest box (mean $\pm \mathrm{SE}$, min/hen-d) by individual laying hens in an enriched colony housing

TS was $63.7 \pm 1.4$ and $35.9 \pm 0.9 \mathrm{~min} / \mathrm{hen}-\mathrm{d}$ during the light and laying period, respectively. As depicted in Figure 2, there were considerable inter-hen variations in daily time spent in the nest box. Expressing the variability in terms of coefficient of variation $(\mathrm{CV})$, the values were $56.4 \%$ and $61.7 \%$ for the light and laying period, respectively. It was possible to identify the hens that used the nest boxes habitually during the laying period (05:00 to 11:00) and those that kept visiting the nest boxes even after the laying period.

In this experiment, most of the hens spent extra time in the nest box after the laying period. Specifically, $26.7 \%$ of them used the nest box predominantly during the laying period, with no significant difference in TS between the laying and light periods (Hens \# 2, 5, 8, 9, 10, 12, 18, 21, 28, 29, 30, 32, 36, 37, 54, and 55), whereas $73.3 \%$ of the hens used the nest box during the laying period and kept using the nest box after the laying period.

\subsection{Daily frequency of visits to nest box (FV)}

All exploring and laying visits to the nest box by the hens were registered, from which FV could be quantified for each of the 60 hens. The daily FV of individual hens is presented in Figure 3.
There was no statistical evidence that $\mathrm{FV}$ was influenced by time (day) for the light period $\left(\mathrm{F}_{1,171.7}=0.02, p=0.87\right)$ or the laying period $\left(\mathrm{F}_{1,183.8}=0.13, p=0.59\right)$. Therefore, data from all days of monitoring were pooled to analyze variability in the FV among the individual birds. FV was $23.4 \pm 0.7$ and $10.4 \pm 0.3$ visits per hen per day for the light and laying period, respectively. CV among the hens in FV was $67.0 \%$ and $70.2 \%$ for the light and laying period, respectively, showing considerable variability among the individual hens in the ECH.

Quantification of the hen-specific number of visits per egg laid in the group nest boxes was not possible with the current setup of the housing and instrumentation systems. The average VE were $25.7 \pm 0.8$ and $11.4 \pm 0.4$ visits per egg laid in the nest box, for the light and laying periods respectively. In general, use of the nest box was more intensive in the morning (05:00 to 11:00) or laying period and mild in the rest of the day. Simultaneous occupancy of the nest boxes and the evolution hour-by-hour of the time spent in the nest box (min/hr-hen) and the frequency of visits to nest box (\# visits/hr-hen) are depicted in Figure 4. 


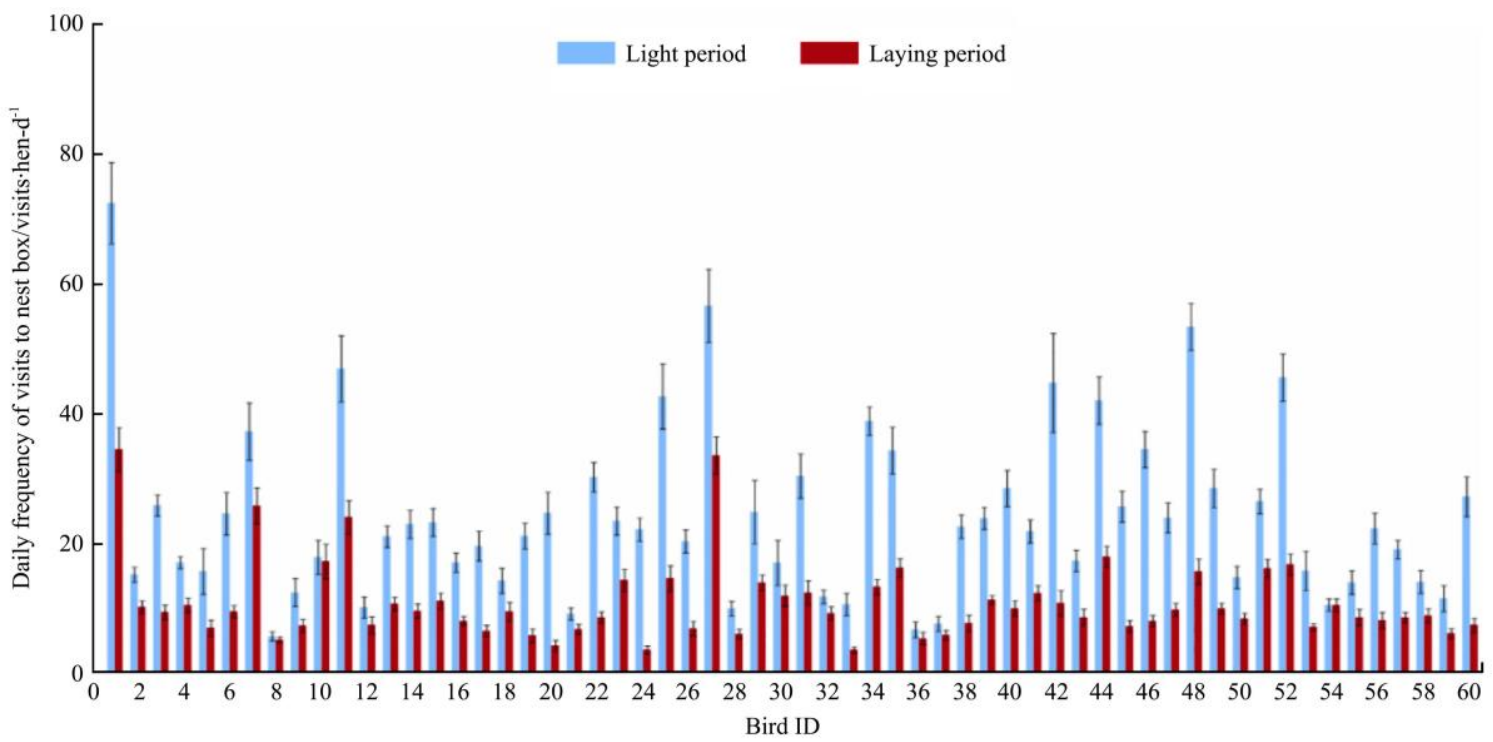

Note: The blue bars represent visit frequency during light period (05:00-21:00) while the red bars represent visit frequency during laying period (05:00-11:00).

Figure 3 Variation in daily frequency of visits to nest box (mean \pm SE, visits/hen-d) by individual laying hens in an enriched colony housing

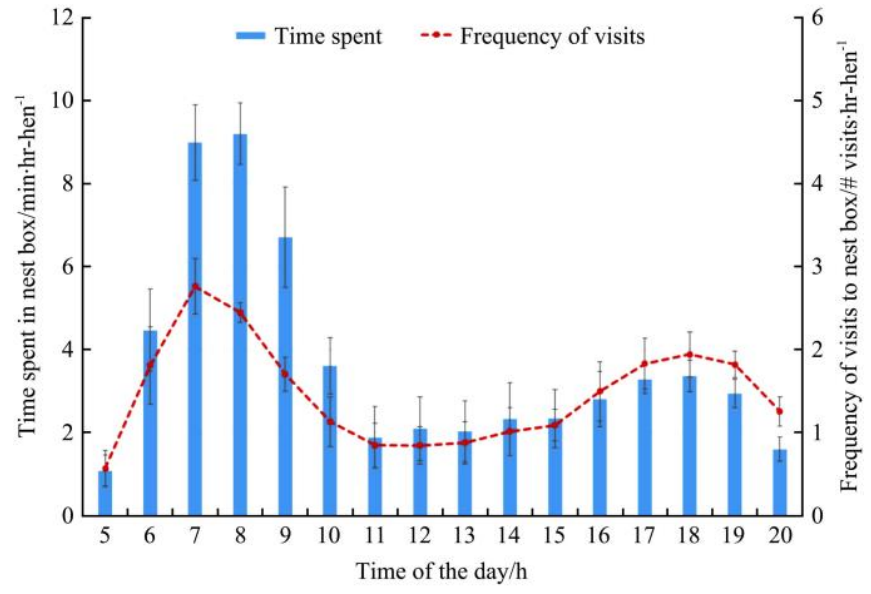

Figure 4 Hourly time spent in the nest box (min/hr-hen) and frequency of visits to nest box (visits/hr-hen) by the laying hens during the experiment period (pooled data of 60 hens over $12 \mathrm{~d}$ )

Hourly TS and FV changed considerably during the day. The peaks of hourly TS and FV coincided between 07:00 and 09:00 and followed the same pattern as the diurnal profile of nest box occupancy. They showed a parabolic pattern during the laying period, where hourly TS and FV increased until 08:00 and then decrease until the end of the laying period at 11:00.

3.3 Maximum simultaneous occupancy (SO) in the nest box, oviposition time (OT) and place (OP)

SO changed with time throughout the day. The maximum occupancy, $29.0 \% \pm 0.4 \%$, occurred between 07:00 and 09:00, within $4 \mathrm{~h}$ after the light came on at 05:00. After this peak time, FV decreased and maintained at low levels until lights off at 21:00 (Figure 5).

During OT, three distinct phases of egg production in the nest boxes were observed: 1) Initial phase (no egg laying despite nest visit) featuring start of nest exploration and increase in nest occupancy, which lasted from 05:00 to 06:30 when the first egg was laid in the nest box (blue rectangle in Figure 5); 2) Peak phase featuring peak egg laying and nest occupancy which lasted from 06:30 to 09:40 when egg laying started decreasing. In this phase, egg-laying followed a linear trend with a rate of $0.24 \pm 0.01$ nest eggs/min (green rectangle in Figure 5); 3) Late phase featuring reduced rate of laying (non-linear trend) and nest occupancy from 09:40 to 11:00 (yellow rectangle in Figure 5).

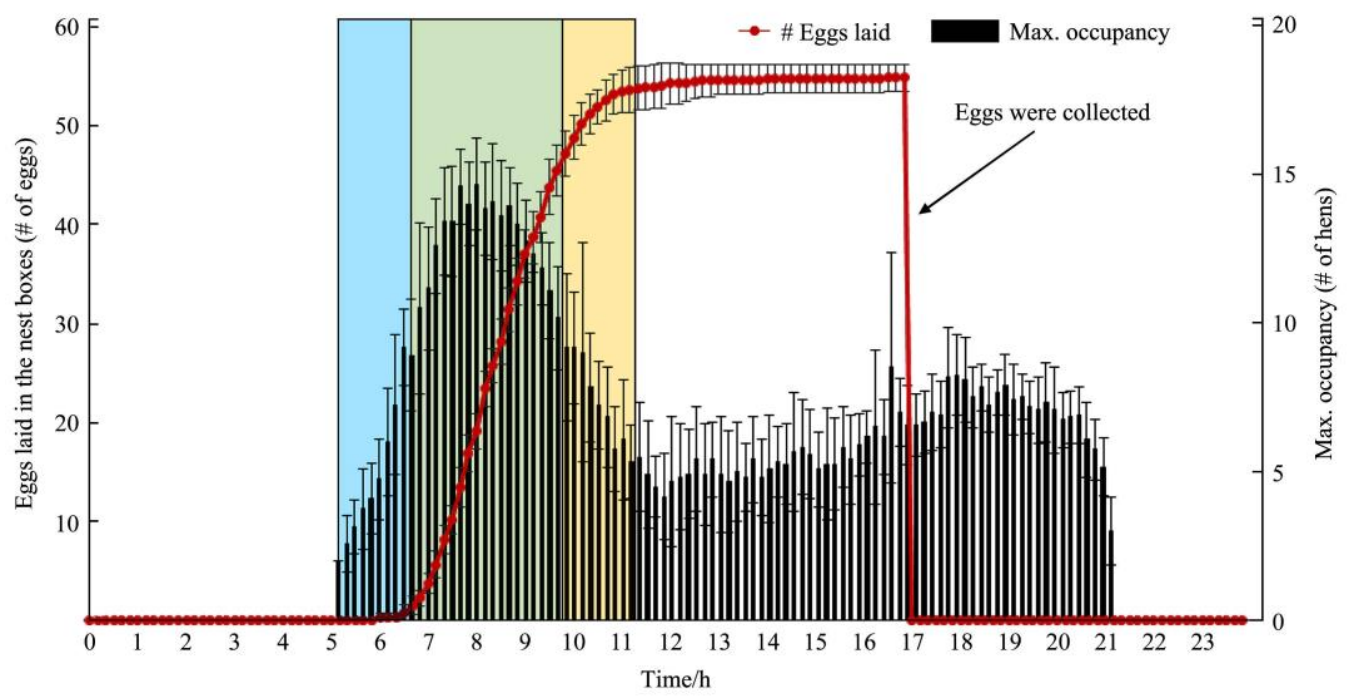

Note: The blue, green and yellow rectangles represent, respectively, the initial phase, peak phase, and late phase. Lights came on at 05:00 and went off at 21:00.

Figure 5 Diurnal profile of nest box maximum occupancy by the laying hens and cumulative registered number of eggs in egg collectors in an enriched colony housing module 
The OP was characterized by the nest, middle or scratch eggs. Most of the nest eggs (82.9\%) were laid in the nest box between 06:30 and 09:40, which partially coincided with the period of maximum nest box occupancy (07:00 to 09:00). As expected, the majority $(95.1 \% \pm 0.6 \%)$ of the daily eggs were laid in the nest box, while $3.8 \% \pm 0.9 \%$ eggs were laid in the scratch area, and only a few $(1.1 \pm 0.6 \%)$ were laid in the middle area.

\subsection{Patterns in nest box usage and association during nesting}

The usage of nest box during laying period differed among the hens. After evaluation of all individual nest box usage data, 5 groups of nesting patterns were established: 1) $15 \%$ presented clear nesting pattern with few or no random visits (FV $\leq 10.4$ visits/d); 2) $45 \%$ presented clear nesting pattern, with moderate nest usage (TS $\leq 35.9 \mathrm{~min} / \mathrm{d}$ ) and several random visits (FV > 10.4 visits/d); 3) $8.3 \%$ of the hens presented clear nesting pattern and used the nest box intensively (TS $>35.9 \mathrm{~min} / \mathrm{d}$ ) during the laying period, with several random visits (FV > 10.4 visits/d); 4) $21.7 \%$ of the hens presented no clear nesting pattern and had intense use of the nest box (TS > $35.9 \mathrm{~min} / \mathrm{d}$ ); and 5) $10 \%$ of the hens presented no clear nesting pattern and had a moderate presence in the nest box (TS $\leq$ $35.9 \mathrm{~min} / \mathrm{d}$ ) (Figure 6).
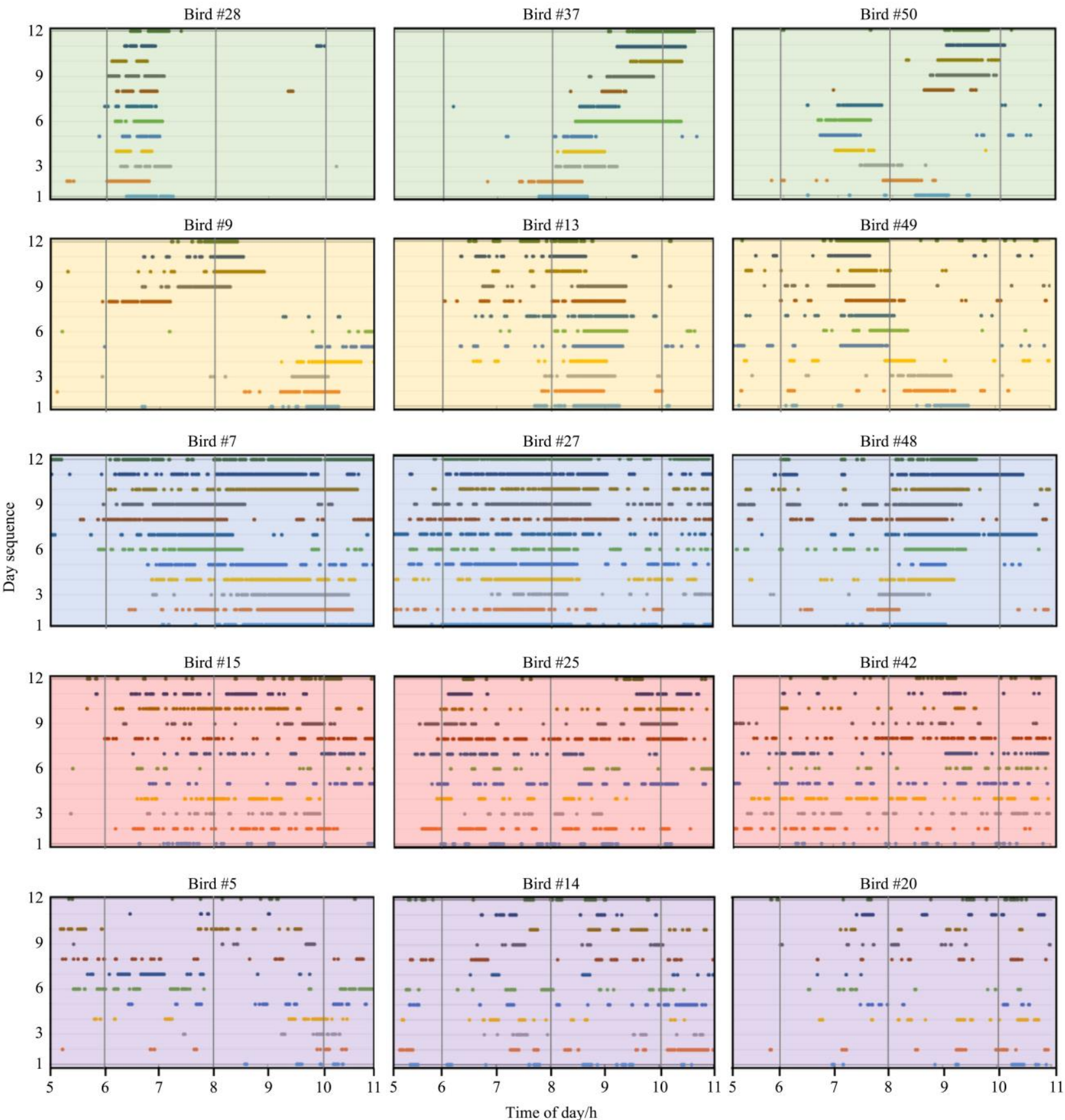

Legend

\section{Nest pattern groups: $\square 1 \square 2 \square 3 \square 4 \square 5$}

Day sequence: $\quad 1 \bullet 2 \bullet 3 \bullet 4 \bullet 5 \bullet 6 \bullet 7 \bullet 8 \bullet 9 \bullet 10 \bullet 11 \bullet 12$

Note: Each colored rectangle represents one different nesting pattern group: 1) There is clear nesting pattern, with few or no random nest visits (green shade), 2) There is clear nesting pattern, with moderate use of the nest box and several random nest visits (yellow shade), 3) There is clear nesting pattern, with intense use of nest box and several random nest visits (blue shade), 4) There is no clear nesting pattern, with intense use of nest box (red shade), and 5) There is no clear nesting pattern, with moderate or low use of nest box (purple shade).

Figure 6 Samples of the presence of individual hens in the nest box during the laying period (05:00-11:00) over 12 consecutive days 
The day-to-day variation in nesting behavior of the laying hens was examined by evaluating the dynamics of the main nest visit for the same hen over the experiment period. Clear nesting pattern was observed in $68.3 \%$ of the hens. Specifically, from the $68.3 \%$ hens, $29 \%$ visited the nest box daily at the same time (see hen \#28 in Figure 6), 27\% visited the nest box earlier every day (see hen \#49 in Figure 6), 20\% visited the nest box later every day (see hen \#37 in Figure 6), and 24\% presented a mix of earlier and later visits to the nest box (see hen \#50 in Figure 6).

During the laying period (05:00-11:00), a higher degree of nesting association among the hens occurred more often when the time of nesting together was low, and vice versa. Specifically, 29 hens spent at least $10 \%$ of their time together in 9 out of 12 days, 8 hens spent at least $40 \%$ of their time together in 5 out of 12 days, and 4 hens spent at least $80 \%$ of their time together in one day only (Figure 7)

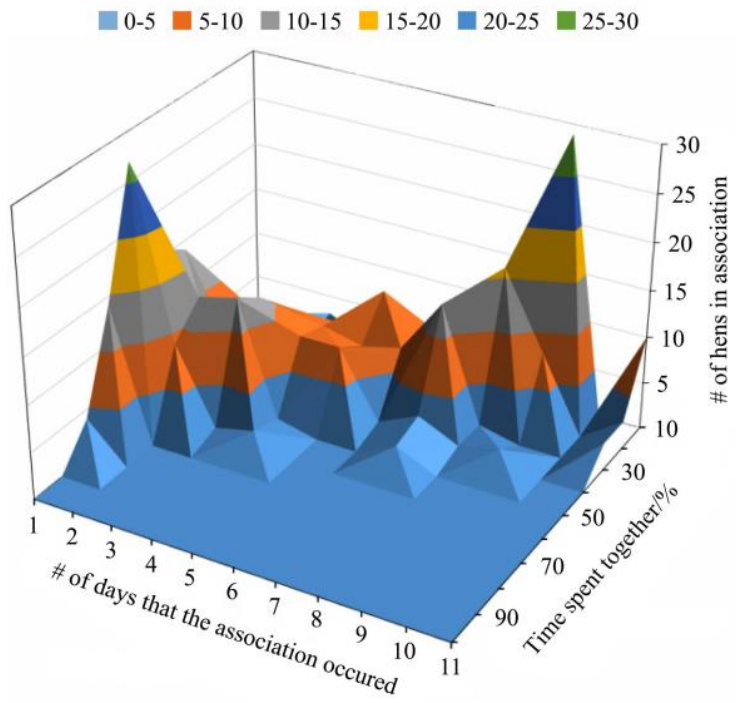

Note: The association refers to the number of hens ( $Z$ axis) that spent their nesting time together (Y-axis) for the number of days (X-axis) over the 12-day experiment period.

Figure 7 Association of laying hens in the nest box during the laying period (05:00 to 11:00)

\section{Discussion}

The RFID system was only mounted in the top tier of the ECH module due to restricted resources and to allow video recording for system performance verification. Consequently, during the experiment period, the group-based variables (OT, OP, VE and SO) were replicated only repeated measures. In addition, the amount of hens involved was quite low and the duration of the experiment period was relatively brief. It should be observed that the research did not address measurements such as aggression or frustration that could occur when nests are crowded. The findings should therefore be treated as descriptive; further validation involving replications and more hens is prudent before solid conclusions may be reached.

Use of the RFID technology provided unique individual information that helped to understand the dynamics of nest box usage and nest egg laying and to identify hens that potentially overused the nest boxes than others. This study, however, could not discern the cause for certain hens to spend more time in the nest. Nevertheless, it may be postulated that social hierarchy played a role in that dominant hens intimidated the subordinate ones, making them delay their oviposition time or just lay eggs in a different place ${ }^{[34,35]}$. Alternatively, the subordinate hens could have used the nest boxes not only for laying eggs but as a refuge shelter from the dominant ones ${ }^{[36]}$. The current study, however, did not quantify the social hierarchy of the hens.

TS during the $6 \mathrm{~h}$ laying period $(35.9 \pm 0.9, \mathrm{~min} / \mathrm{hen}-\mathrm{d})$ was approximately $56 \%$ of the TS during the $16 \mathrm{~h}$ light period $(63.7 \pm 1.4, \mathrm{~min} / \mathrm{hen}-\mathrm{d})$. This result paralleled the findings reported previously about the influence of nest-floor slope on nest choices, where it was found that birds could spend 10-90 $\mathrm{min}$ in the nest when laying an $\operatorname{egg}^{[37]}$. Other studies have reported that hens occupied nest box for approximately $40 \mathrm{~min} / \mathrm{d}^{[38]}, 29 \mathrm{~min}$ prior to egg laying with extended $6.5 \mathrm{~min}$ before leaving the nest box ${ }^{[39]}$. The use of nest box after laying period is not recommended as the nest mat would be highly prone to excreta deposition that could, in turn, lead to dirty eggs ${ }^{[40]}$.

The hens were observed to have different individual nesting patterns, and only $26.7 \%$ of them used the nest box predominantly during the laying period. The overall VE during the light period $(25.7 \pm 0.8$, visits/egg) was approximate twice the value for the laying period (11.4 \pm 0.4 , visits/egg). A high number of nest visit per egg $(40.3 \pm 11.4)$ has been observed when testing preferences of nest options in groups of 20 hens ${ }^{[41]}$. Besides, in an experiment to investigate the effect of nest size on the nesting behavior it was found that the number of visits per egg laid was $34.9 \pm 3.7^{[42]}$. The revisit can be explained as the exploratory behavior of the hens ${ }^{[43]}$, or an indication that the enrichments inside the colony were not enough to keep them attracted. It reinforces that the nest box area has attractiveness beyond the purpose of laying the egg; however, this practice should be discouraged to avoid manure deposition on the nest mat.

The number of hens nesting simultaneously as a function of time during the day showed similar behavior through the experiment period. The visits started right after the lights came on at 05:00 and increased to a peak of $29.0 \pm 0.4 \%$ occupancy (from 07:00 to 09:00). After the peak, the nesting synchronization decreased and maintained a minimum level until the lights went off (21:00). Laying hens have been shown to use nest boxes mostly in the morning, followed by the midday and evening ${ }^{[44]}$. Our results also agreed with previous findings that when evaluating the influence of nest site on the behavior of laying hens the main laying period for hens in commercial aviary systems was between 1 to $4 \mathrm{~h}$ after lights were turned on ${ }^{[45]}$. The concentration of hens in the nest box during the peak time may be explained by the phenomenon of gregarious nesting, also known as the preference for occupied nests ${ }^{[19,46]}$, attributing this behavior to the sense of protection $^{[42]}$.

This experiment found that $83 \%$ of the nest eggs were laid proportionally in time within the period between $1 \mathrm{~h}$ and $30 \mathrm{~min}$ and $4 \mathrm{~h}$ and $40 \mathrm{~min}$ after lights-on (05:00), with an average laying rate of $0.24 \pm 0.01 \mathrm{eggs} / \mathrm{min}$ in the nest box. This pattern coincided mostly with the peak of simultaneous nest box occupancy period (from 07:00 to 09:00). Previous research has shown a nonlinear pattern of egg laying with a peak of eggs laid around $3.5 \mathrm{~h}^{[47]}$ or 3.5-4.5 $\mathrm{h}^{[48]}$ after lights-on. In an investigation of the nest use and patterns of egg laying of 4 different strains of laying hens in aviary system, it was found that all strains presented a peak of nest usage at 08:00 (3 $\mathrm{h}$ after the lights came on $)^{[44]}$. In that study, brown hens (Hy-Line and Bovan) showed similar behavior with $85 \%$ of the nest eggs laid from 06:00 to 10:00, while the white hens (Hy-Line W36 and Dekalb White) laid about 55\% of their daily nest eggs during the same period.

The three distinct phases egg production in nest boxes indicate 
that the hens were exposed to a less competitive nest box during the third phase, which suggests that oviposition delay could be motivated by stress and its impact on hen's physiology ${ }^{[35]}$. It is important to understand the motivations of oviposition delay, especially considering that such delay may cause abnormal eggshell formation ${ }^{[35]}$, impair reproduction by the cessation of egg laying $^{[49]}$, and trigger floor eggs in aviary or free-range housing systems $^{[50]}$.

It takes about $24 \mathrm{~h}$ after ovulation to complete the formation of an egg, which is divided into the following: $4 \mathrm{~h}$ for addition of the albumen layers to the yolk as it passes along the oviduct; $5 \mathrm{~h}$ for the membranes formation in the tubular isthmus and absorption of water and salts in the shell gland; and $15-16 \mathrm{~h}$ for the shell calcification $^{[51,52]}$. However, for the hens with identified nesting patterns, the day-to-day pattern of oviposition time varied considerably, and hens were classified into four different groups: 1) hens that visited the nest box every day at the same time, 2) each day earlier, 3) each day later or 4) mixed periods (earlier and later). While this experiment could not identify if a specific hen indeed laid an egg when inside the nest box, this observation suggests that the $24 \mathrm{~h}$ period between egg laying is not consistent among individuals and need further investigation. A few hens did not visit the nest box during laying period on some days. This behavior could be related to physiology when considering that the hens pause laying between clutches ${ }^{[33,54]}$, social factors such as the presence of dominant hens ${ }^{[34]}$, lack interest in delaying oviposition to a less competitive time ${ }^{[35]}$, or specific preference of the scratch and perch areas over the nest box. The rearing environment affects nest use, and individual laying hens might perceive nest sites differently ${ }^{[5]}$.

Although various degrees of the association during nesting was detected, it was not sufficient to conclude that the hens had social preferences, or that their oviposition cycle was synchronized. Social preferences of laying hens expressed by close active and resting proximities were not found in a group of 15 hens over 8 weeks based on three 15-min scanning periods (one day per week for active space use, and three days per week for roosting association $)^{[56]}$.

As expected, most of the eggs were laid in the nest box area $(95.1 \% \pm 0.6 \%$ ), while $3.8 \% \pm 0.9 \%$ of the eggs were laid in the scratch area and even a lower proportion $(1.1 \% \pm 0.6 \%)$ of eggs were laid in the middle open area. In furnished cages, similar results were found where $91.7 \%$ of the total eggs were laid in the nest box, $7.2 \%$ in the scratch area, and $1.1 \%$ in the perches area ${ }^{[47]}$. In a recent study with aviary systems, the OP was quite similar to the findings in $\mathrm{ECH}$, where $90.5 \%-94.9 \%$ of the eggs were laid in the nest boxes, and $2.3 \%-4.4 \%$ of the eggs were laid on the litter ${ }^{[44]}$.

\section{Conclusions}

This study demonstrates that the validated UHF-RFID system can be successfully used to continuously and automatically monitor the nesting behavior of individual hens kept in a group. Application of the RFID system with an enriched colony housing (ECH) revealed significant variability in nesting behavior among individual laying hens. The degree of temporal variation in nesting behavior also varies considerably among individual hens in the ECH. The RFID system will enable researchers to examine the impacts of resource allocations on nesting behaviors of laying hens, which may in turn help guiding the design of alternative hen housing systems.

\section{Acknowledgements}

Financial support for procurement of the electronic devices and supplies for the behavioral monitoring/tracking system was provided in part by the Iowa Egg Council Endowed Professorship fund awarded to Hongwei Xin. We also acknowledge the financial support of the Brazilian National Council for Scientific and Technological Development $(\mathrm{CNPq})$ and the Federal University of Rondonópolis (UFR) to Jofran Oliveira for his $\mathrm{PhD}$ study program at Iowa State University (ISU). The enriched colony modules used in this study were donated by Big Dutchman Company and are acknowledged with gratitude. We further express our appreciation to the ISU research personnel, especially Suzanne Leonard, Dr. Brett Ramirez and Dr. Down Koltes for their assistance and consultation.

\section{[References]}

[1] Lay D C, Fulton R M, Hester P Y, Karcher D M, Kjaer J B, Mench J A, et al. Hen welfare in different housing systems. Poultry Science, 2011; 90(1): 278-294.

[2] Appleby M C, Hughes B O. Welfare of laying hens in cages and alternative systems: environmental, physical and behavioural aspects. Worlds Poult Sci J, 1991; 47(2): 109-128.

[3] Tauson R. Management and housing systems for layers-effects on welfare and production. Proc Nutr Soc, 2005; 61(3): 477-490.

[4] Ochs D S, Wolf C A, Widmar N J O, Bir C. Consumer perceptions of egg-laying hen housing systems. Poultry Science, 2018; 97(10): 3390-3396.

[5] Mench J A. Farm animal welfare in the U.S.A.: Farming practices, research, education, regulation, and assurance programs. Appl Anim Behav Sci., 2008; 113(4): 298-312.

[6] Chai L, Xin H, Zhao Y, Wang T, Soupir M, Liu K. Mitigating ammonia and PM generation of cage-free henhouse litter with solid additive and liquid spray. Trans ASABE, 2018; 61(1): 287-294.

[7] Cooper J J, Appleby M C. Nesting behaviour of hens: Effects of experience on motivation. Appl Anim Behav Sci., 1995; 42(4): 283-295.

[8] Struelens E, Van Nuffel A, Tuyttens F A M, Audoorn L, Vranken E, Zoons $\mathrm{J}$, et al. Influence of nest seclusion and nesting material on pre-laying behaviour of laying hens. Appl Anim Behav Sci., 2008; 12(1-2): 106-119.

[9] Struelens E, Tuyttens F A M, Janssen A, Leroy T, Audoorn L, Vranken E et al. Design of laying nests in furnished cages: influence of nesting material, nest box position and seclusion. Br Poult Sci., 2005; 46(1): 9-15.

[10] Zupan M, Kruschwitz A, Huber-Eicher B. The influence of light intensity during early exposure to colours on the choice of nest colours by laying hens. Appl Anim Behav Sci., 2007; 105(1-3): 154-164.

[11] Ringgenberg N, Fröhlich E K F F, Harlander-Matauschek A, Toscano M J, Würbel H, Roth B A. Effects of variation in nest curtain design on pre-laying behaviour of domestic hens. Appl Anim Behav Sci., 2015; 170 $34-43$.

[12] Nicol C J. Development, direction, and damage limitation: Social learning in domestic fowl. Anim Learn Behav., 2004; 32(1): 72-81.

[13] Krause E T, Schrader L. High, low, or familiar? Nest site preferences of experienced laying hens. Br Poult Sci., 2018; 59(4): 359-364.

[14] Cooper J J, Appleby M C. Individual variation in prelaying behaviour and the incidence of floor eggs. Br Poult Sci., 1996; 37(2): 245-253.

[15] Freire R, Appleby M C, Hughes B O. Assessment of pre-laying motivation in the domestic hen using social interaction. Anim Behav., 1997; 54(2): 313-319.

[16] Reynard M, Savory C. Oviposition delays induced by social stress are reversed by treatment with the beta-adrenergic blocking agent propranolol. Poult Sci., 1997; 76(9): 1315-1317.

[17] Appleby M C, Smith S F. Design of nest boxes for laying cages. $\mathrm{Br}$ Poult Sci., 1991; 32(4): 667-678.

[18] Lundberg A, Keeling L J. The impact of social factors on nesting in laying hens (Gallus gallus domesticus). Appl Anim Behav Sci., 1999; 64(1): 57-69.

[19] Riber A B. Development with age of nest box use and gregarious nesting in laying hens. Appl Anim Behav Sci., 2010; 123(1-2): 24-31.

[20] Appleby M C, Maguire S N, McRae H E. Nesting and floor laying by 
domestic hens in a commercial flock. Br Poult Sci., 1986; 27(1): 75-82.

[21] Shi H P, Zheng W C, Tu J, Li B M. Reducing feather pecking and cloacal cannibalism by providing layer breeders with nest boxes in colony cages for natural mating. Int J Agric Biol Eng, 2018;11(6): 27-32.

[22] Voulodimos A S, Patrikakis C Z, Sideridis A B, Ntafis V A, Xylouri E M. A complete farm management system based on animal identification using RFID technology. Comput Electron Agric., 2010; 70(2): 380-388.

[23] Brown-Brandl T M, Eigenberg R A. Development of a livestock feeding behavior monitoring system. Am Soc Agric Biol Eng, 2011; 54(5): 1913-20

[24] Maselyne J, Saeys W, De Ketelaere B, Mertens K, Vangeyte J, Hessel E F, et al. Validation of a high frequency radio frequency identification (HF RFID) system for registering feeding patterns of growing-finishing pigs. Comput Electron Agric., 2014; 102: 10-18.

[25] Li G, Zhao Y, Hailey R, Zhang N, Liang Y, Purswell J L. An ultra-high frequency radio frequency identification system for studying individual feeding and drinking behaviors of group-housed broilers. Animal, 2019; 13(9): 2060-2069.

[26] Nakarmi A, Tang L, Xin H. Automated tracking and behavior quantification of laying hens using 3D computer vision and radio frequency identification technologies. Trans ASABE, 2014; 57: 1455-1472.

[27] Sales G T, Green A R, Gates R S, Brown-Brandl T M, Eigenberg R A. Quantifying detection performance of a passive low-frequency RFID system in an environmental preference chamber for laying hens. Comput Electron Agric., 2015; 114: 261-268.

[28] Campbell D L M, Hinch G N, Downing J A, Lee C. Outdoor stocking density in free-range laying hens: effects on behaviour and welfare. animal, 2017; 11(6): 1036-1045.

[29] Siegford J, Berezowski J, Biswas S, Daigle C, Gebhardt-Henrich S, Hernandez C, et al. Assessing Activity and Location of Individual Laying Hens in Large Groups Using Modern Technology. Animals, 2016; 6(2): 10 .

[30] Marx G, Klein S, Weigend S. An automated nest box system for individual performance testing and parentage control in laying hens maintained in groups. Arch fur Geflugelkd, 2002; 66(3): 141-144.

[31] Thurner S, Wendl G, Preisinger R. Funnel nest box: a system for automatic recording of individual performance and behaviour of laying hens in floor management. XII Eur Poult Conf Italy, Sept 10-14, 2006; pp.610-611.

[32] Li L, Zhao Y, Oliveira J, Verhoijsen W, Liu K, Xin H. A UHF RFID system for studying individual feeding and nesting behaviors of group-housed laying hens. Trans ASABE, 2017; 60(4): 1337-1347.

[33] Oliveira J L, Xin H, Wu H. Impact of feeder space on laying hen feeding behavior and production performance in enriched colony housing. Animal, 2018; 2004: 1-10.

[34] Rietveld-Piepers B, Blokhuis H J, Wiepkema P R. Egg-laying behaviour and nest-site selection of domestic hens kept in small floor-pens. Appl Anim Behav Sci., 1985; 14(1): 75-88.

[35] Reynard M, Savory C J. Stress-induced oviposition delays in laying hens: Duration and consequences for eggshell quality. Br Poult Sci., 1999; 40(5): 585-591.

[36] Shimmura T, Eguchi Y, Uetake K, Tanaka T. Effects of separation of resources on behaviour of high-, medium- and low-ranked hens in furnished cages. Appl Anim Behav Sci., 2008; 113(1-3): 74-86.
[37] Stämpfli K, Roth B A, Buchwalder T, Fröhlich E K F. Influence of nest-floor slope on the nest choice of laying hens. Appl Anim Behav Sci., 2011; 135(4): 286-292.

[38] Wall H, Tauson R, Elwinger K. Pop hole passages and welfare in furnished cages for laying hens. Br Poult Sci., 2004; 45(1): 20-27.

[39] Cronin G M, Barnett J L, Hemsworth P H. The importance of pre-laying behaviour and nest boxes for laying hen welfare: a review. Animal Production Science, 2012; 52(7): 398-405

[40] Tactacan G B, Guenter W, Lewis N J, Rodriguez-Lecompte J C, House J D Performance and welfare of laying hens in conventional and enriched cages. Poult Sci., 2009; 88(4): 698-707.

[41] Buchwalder T, Fröhlich E K. Assessment of colony nests for laying hens in conjunction with the authorization procedure. Appl Anim Behav Sci., 2011; 134(1-2): 64-71.

[42] Ringgenberg N, Fröhlich E K F F, Harlander-Matauschek A, Würbel H Roth B A. Does nest size matter to laying hens? Appl Anim Behav Sci., 2014; 155: 66-73.

[43] Wood-Gush D G M, Vestergaard K. Exploratory behavior and the welfare of intensively kept animals. J Agric Ethics., 1989; 2(2): 161-169.

[44] Villanueva S, Ali A B A, Campbell D L M, Siegford J M. Nest use and patterns of egg laying and damage by 4 strains of laying hens in an aviary system. Poult Sci., 2017; 96(9): 3011-3020.

[45] Lentfer T L, Gebhardt-Henrich S G, Fröhlich E K F, von Borell E. Influence of nest site on the behaviour of laying hens. Appl Anim Behav Sci., 2011; 135(1-2): 70-77.

[46] Appleby M C, McRae H E, Peitz B E. The effect of light on the choice of nests by domestic hens. Appl Anim Ethol., 1984; 11(3): 249-254.

[47] Hunniford M E, Torrey S, Bédécarrats G, Duncan I J H H, Widowski T M. Evidence of competition for nest sites by laying hens in large furnished cages. Appl Anim Behav Sci., 2014; 161: 95-104.

[48] Hunniford M E, Woolcott C, Siegford J, Widowski T M. Nesting behavior of Hy-Line hens in modified enriched colony cages. Poult Sci., 2017; 96(6):1515-1523.

[49] Odihambo Mumma J, Thaxton J P, Vizzier-Thaxton Y, Dodson W L. Physiological stress in laying hens. Poult Sci., 2006; 85(4): 761-769.

[50] Oliveira J L, Xin H, Chai L, Millman S T. Effects of litter floor access and inclusion of experienced hens in aviary housing on floor eggs, litter condition , air quality, and hen welfare. Poultry Science, 2019; 98(4) 1664-1677.

[51] Taylor T G. How an eggshell is made. Scientific American, 1970 222(3): 88-97.

[52] Perrins C M. Eggs, egg formation and the timing of breeding. Ibis (Lond 1859), 1996; 138(1): 2-15.

[53] Wolc A, Jankowski T, Arango J, Settar P, Fulton J E, O'Sullivan N P, et al Investigating the genetic determination of clutch traits in laying hens. Poult Sci., 2019; 98(1): 39-45.

[54] Samiullah S, Roberts J, Chousalkar K. Oviposition time, flock age, and egg position in clutch in relation to brown eggshell color in laying hens. Poult Sci., 2016; 95(9): 2052-2057.

[55] Hunniford M E, Widowski T M. Rearing environment and laying location affect pre-laying behaviour in enriched cages. Appl Anim Behav Sci., 2016; 181: 205-213.

[56] Abeyesinghe S M, Drewe J A, Asher L, Wathes C M, Collins L M. Do hens have friends? Appl Anim Behav Sci., 2013; 143(1): 61-66. 